\title{
Samatradução: a audição tradutória
}

\section{Samatranslation: the translational audition}

Leandra Yunis*

Resumo: No presente artigo a autora comenta algumas operações tradutórias do método experimental desenvolvido em sua prática com a tradução direta do persa de alguns poemas místicos. Com base na teoria da imaginação de Ibn Arabi (1165-1240) e na doutrina da audição mística de Alghazali (1058-1111), propõe-se a adaptação de alguns procedimentos místicos para fins tradutórios. A reescrita de um gazal do mestre sufi Jalal Uddin Rumi (12071273) serve de fio condutor para demonstrar como seria a "audição tradutória" pelo método intuitivo.

Palavras-chave: Tradução; Sufismo; Poesia Persa; Jalal Uddin Rumi (12071273); Hermenêutica.

Abstract: In this article the author comments on her experimental method that has been developed to translate some mystical poems directly from Persian to Portuguese. Based on the imagination theory of Ibn Arabi (11651240 ) and the mystical audition instructions of Alghazali (1058-1111), it's suggested to use some mystical procedures for translation purposes. By showing the way of rewriting a ghazal of Jalal Uddin Rumi (1207-1273), the Sufi master, the author demonstrates how to do a "translational auditon" through the intuitive method.

\footnotetext{
* Historiadora pela USP com mestrado sobre a relação interestética entre poesia e dança no Programa de Pós-Graduação em Língua, Literatura e Cultura Árabe e do Oriente Médio, Departamento de Letras Orientais - Árabe /USP, e doutorado sobre a história da dança no islã e a tradução do tema na poesia de Rumi pelo Programa de Pós-graduação em Estudos Judaicos e Árabes, Departamento de Letras Orientais - Árabe, USP, pesquisadora de tradições coreográficas orientais (DRT 32403) e tradutora de poesia persa clássica e contemporânea. E-mail: leyunis@gmail.com
} 
Keywords: Translation; Sufism; Persian Poetry; Jalal Uddin Rumi (1207-1273); Hermeneutics.

Ao traduzir a poesia de Jalal Uddin Rumi (1207-1273) acabei por ensaiar uma metodologia que combinava parâmetros literários, históricos e místicos, que denominei, na ocasião, samatradução, pois o prefixo samá, do árabe "audição", é um termo utilizado pelos místicos muçulmanos para denominar ritos devocionais heterodoxos com audição de música, poesia e dança (YUNIS 2017). Orientando-me pelos princípios da audição sufi, desenvolvi essa espécie de "audição tradutória" da poesia com base nas noções de imaginação criativa, segundo a teoria do andalusino lbn Arabi (1165-1240), e de gnose intuitiva, estabelecida pelo persa Alghazali (10581111). Apresento a seguir uma síntese de tais noções pensadas para fins tradutórios e, em seguida, explicito o processo intuitivo-criativo na tradução de um gazal de Rumi.

O filósofo místico Ibn Arabi acreditava que a criação poética poderia advir de um estado imaginativo que propicia a conexão profunda e arcana entre a consciência humana e o mistério divino, por meio do qual as verdades superiores se revelariam em formas arquetípicas e simbólicas (1980). Elucidando tal teoria, o poeta e crítico Adonis explica que este "simbolismo se desenha sempre numa forma, que não é fixa, mas que é uma 'casa' visível para um habitante invisível. A forma é um corpo: o corpo do significado. Entre a 'forma' e o 'significado' existe uma unidade 'imagem'” (1990: 264-265). A “imagem”, portanto, seria o reflexo de uma verdade intuitiva que se exprime de forma sensível na realização poética. Podemos presumir desta perspectiva que aquela conexão arcana se restabeleça no tradutor ao ler o poema místico a ser traduzido, pois, embora pareça historicamente impossível, o caminho do insight original pode ser retrilhado se considerarmos que as faculdades imaginativas são universais, mesmo não sendo idênticas em todos.

Assim, ao menos no nível da simbolização da própria experiência com o poema em recriação, o tradutor pode, em tese, se tornar veículo daquela verdade espiritual que, sendo acessada novamente de outra perspectiva, emite reflexos renovados no contexto da reescrita. Se isto implica na adaptação da fórmula original para verter criativamente o simbolismo num novo corpo poético, como sugere a explicação de Adonis, isso não afeta, entretanto, o arquétipo, que tampouco é fixo enquanto elemento intermediário da experiência epifânica. Contudo, para que de fato se experimente o poema de uma maneira mística, ao menos da perspectiva sufi, não basta focar no sentido espiritual dos versos. A audição mística da poesia é experiencial, ou seja, deve ser tomada como uma experiência em si e envolve estágios de atenção e aproximação do sentido através da autoconsciência e da intuição, que devem ser desenvolvidas sob parâmetros 
específicos. Uma formulação específica da audição poética foi apresentada neste sentido por Alghazali no século XII (1901: 705-748), que indicava os seguintes estágios para a apreensão mística do poema: 1) Percepção áudiosensorial; 2) sentido literal; 3) sentido afetivo; 4) observação da mutação e pluralidade de sentidos; 5) intelecção; 6) autoconsciência; 7) intuição.

Em termos tradutórios, podemos dizer que os dois primeiros estágios envolvem aquilo que consideramos os aspectos retórico-formais: pela recepção sonora do poema há identificação da cadência rítmica e da melodia; pela apreensão do sentido literal do verso também se identificam alguns de seus elementos formais, como segmentos semânticos e disposições espaciais das imagens etc. Em termos de tradução, o sentido literal do verso ainda não corresponde ao sentido semântico, porque este será construído ao longo das etapas e estágios consecutivos, nos quais incidem fatores variantes de caráter afetivo e intelectivo.

0 terceiro estágio consiste em aplicar o sentido dos versos ao próprio estado emocional e buscar nele uma resposta ou mensagem oculta, ao modo oracular. O leitor/ouvinte interpreta e sente o poema conforme a sua própria condição afetiva, portanto, enquanto tradutor, já o modifica, uma vez que este estado subjetivo influencia nas suas opções e marcas tradutórias e revela a sua relação particular com o texto traduzido.

No quarto estágio, o leitor/ouvinte/tradutor observa que seus estados são mutáveis, que a resposta catalisada no poema não é a única e que o poema também produz nele outros estados, antes desconhecidos. Uma vez que os místicos consideram toda a mutabilidade do mundo proveniente de Deus, essa oscilação interior nada mais é do que a ação divina, que às vezes ilumina ou ofusca nosso entendimento com a única finalidade de produzir a experiência existencial. Com relação à tradução, é quando se reconhece que o texto original não tem sentido fixo e pode ser ressignificado pela multiplicidade de sentidos que as imagens e palavras recebem conforme a condição interior e situação do tradutor ao ler o poema.

No quinto estágio, observa-se que os movimentos da alma também são divergentes do intelecto, o qual observa e compreende as mutações subjetivas por meio de fatores objetivos e de critérios racionais. Assim, o tradutor percebe as diferenças ou similaridades entre o seu contexto existencial e histórico e aquele da vida do autor. Então, busca-se o significado de expressões e termos por meio de estudos em fontes e textos correlatos e se identificam as citações alusivas e expressões proverbiais conforme o contexto de criação e recepção originais.

0 sexto estágio consiste em converter-se em espectador de si mesmo neste movimento investigativo, ter consciência do ato cognitivo atuando na sua relação com o poema em tradução. 0 tradutor supera a dualidade entre 
a identificação subjetiva e a análise intelectiva na medida em que toma consciência do próprio ponto de observação, reconhecendo suas identificações projetivas assim como a sua posição em relação a outras formas de apropriações daquele mesmo texto. Mesmo tendo feito a diferenciação entre si e o autor, o tradutor percebe que essa diferenciação e a própria apreensão do passado são construídas nesse movimento e não estão definidas a priori. Neste sentido, envolve a historicidade (MESCHONNIC 1982), ou seja, situa-se de forma relacional no tempo, e a ressigificação histórica (DILTHEY 1944), isto é, reconhece os elos de significação na dinâmica trans-histórica que mantém o texto vivo. É um movimento harmônico com as análises comparativas de tradutores ou retradutores e permite colocar a própria abordagem e recriação do texto em perspectiva.

No sétimo estágio o ouvinte se relaciona de forma intuitiva com o texto, pois seu coração (ou consciência) está limpo e livre dos reflexos subjetivos, bem como do distanciamento intelectivo. Trata-se de um estado unitivo que, no sentido da tradução, significa encontrar o registro estético, de linguagem e pensamento, adequado para verter o poema. 0 tradutor está familiarizado com o discurso do autor, seu modo de expressar, de dispor as imagens e construir silogismos, bem como com os demais recursos de que se utiliza para atingir a audiência, porém, tais procedimentos só são interessantes ao tradutor quando apropriados ao propósito de recriar o poema na nova língua conforme o contexto da enunciação. 0 propósito do tradutor determina o sentido em sua relação particular com o discurso do autor. Neste estágio as alterações semânticas são intuitivas, nem racionais nem subjetivas.

Vejamos, então, como ocorre a audição tradutória com o gazal 806 (RUMl 1957), escolhido para exemplificar o processo neste artigo.

0 poema no persa original é o seguinte: 


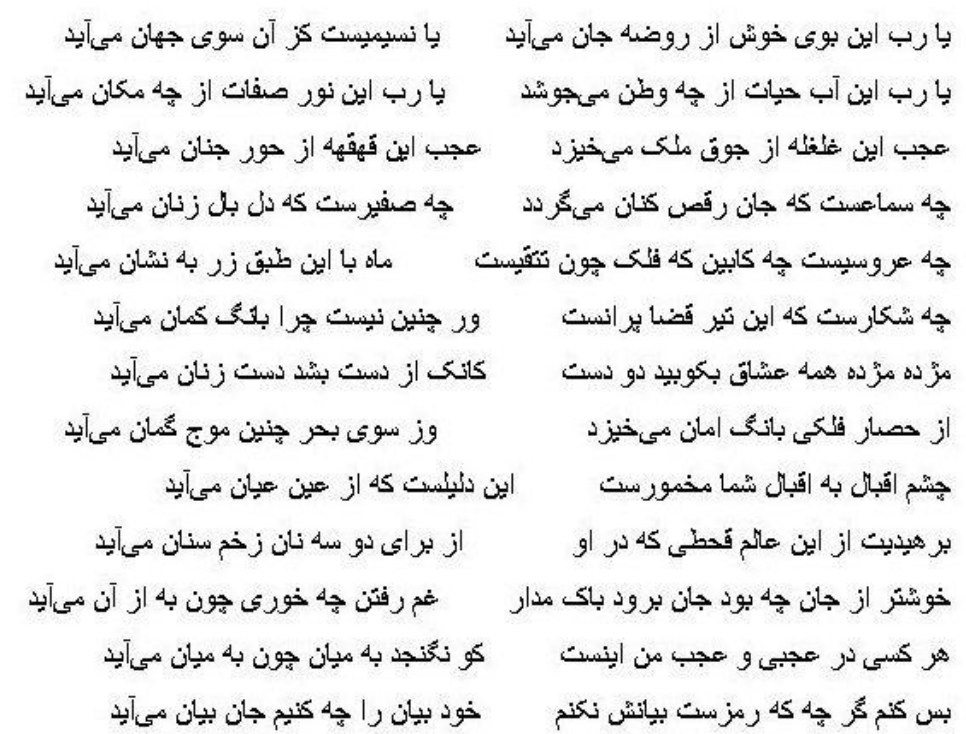

Nota-se, no sentido retórico-formal, que é composto de versos bipartidos com rima anáfora, repetida internamente em ambos os hemistíquios do primeiro verso. Trata-se de uma fórmula oral padrão do gazal persa, que serve para a audiência antecipar o sentido dos versos seguintes, com frequência aferido pelo verbo, que naquele idioma cai naturalmente ao final da frase; portanto, na rima.

Translitero a seguir apenas o primeiro verso, que também guarda por padrão a cadência rítmica do poema:

Yã rab īn būye hūsh az rūzeh-ye jān mi-āyad?

Yā nassīmīst kez ān sūye jahān mi-āyad?

0 primeiro desafio seria estabelecer o aspecto prosódico em que é recitado o verso para poder aferir ao mesmo tempo o ritmo e o sentido literal da frase. Onde se lê "-ye" ou "-e", como em rūzeh-ye, o hífen seguido de sufixo indica uma partícula conectiva não grafada, chamada ezafê e somente aferida por leitura oral, cuja ausência ou presença pode determinar o sentido literal da frase (KAHNEMUYIPUR 2006). Por exemplo, o termo rūzeh-ye jān significa "homilia ou prado da alma". A frase do hemistíquio se traduz literalmente por "ó senhor, esse perfume delicioso, vem do prado/homilia da alma?", contudo, dada a potencial polissemia do verso e também do verbo-rima, lida sem o ezafê significaria "ó senhor, esse perfume delicioso do prado/homilia à alma chega?", mudando bastante o sentido.

No persa também ocorre que algumas palavras podem ter a sua recitação modificada para dar ritmo ao poema. Então poderia acontecer de 
a palavra būye, "perfume", ser recitada como bova-ye, uma vez que o ū é glide 1 , portanto também / $/ \mathrm{e}$, nestes casos, a palavra ganha uma vogal curta a mais. No caso específico de būye não se usa essa distensão, embora seja comum no caso do verbo būdan, "ser", que com frequência se lê bovadan. Ademais, pela mera leitura sem recitação se deduziria que todo “ā" é uma vogal longa / $\mathrm{p}: /$; porém, em algumas posições sua realização é curta /a/. O mesmo acontece para as vogais sinalizadas acima como $\overline{1}$ e $\bar{u}$, que se grafam no original e se transliteram como longas, mas se realizam também de outras formas como /e:/ e /o:/ além de serem glide; ou para o caso das que não se grafam e são, contudo, longas. Isto é algo que divide os linguistas, pois toca no problema da adoção do alfabeto e do sistema de versificação árabe e de sua influência ou não sobre metros possivelmente nativos do persa (DEO; KIPARSKY s/d). Ou seja, mesmo com um conhecimento avançado na língua e nos ritmos poéticos, a dificuldade está em como identificar o metro: se pelo método árabe, extensional, sonoro e nãosilábico, ou pelo persa, tônico e extensional, com uso de sílabas ultralongas.

Como eu não tinha esse domínio, recorri a professores nativos e, portanto, a minha audição não foi sensorialmente pura, mas filtrada pela de outras pessoas. Hoje sou capaz de "ouvir" o verso "cantado" nos seguintes pés e marcação tônica (em negrito), lembrando que este ā se parece mais com um "óoo" para os falantes do português:

Yā rab / īn būye hūsh/ az rūzeh-ye/ jān mi-āyad? /

/ Yā nassīmīst / kez ān sūye / jahān mi-āyad?

0 que retive do aprendizado sobre a dimensão rítmica foi a intenção de manter os pés métricos (que são mais longos do que os gregos) unidos aos segmentos semânticos, isto é, sem cindir palavras e, de preferência, em unidades de sentido autônomas. Na tradução, busquei manter esse traço combinado com a característica oral da não-pontuação, sinalizando pausas com longos espaçamentos para que o leitor pontue o texto durante a recitação. Assim, para este primeiro verso, cuja tradução literal poderia ser "ó Senhor, esse perfume delicioso, vem da homilia de alguém? Não viria daquela outra direção, do além-mundo?", estabeleci a seguinte versão final:

Senhor/ que aroma é esse? Vem da catequese ou do além?

Sem metrificar, contudo, apostei em espaçamentos que sinalizam pausa ou silêncio que preencheriam as lacunas métricas durante a leitura. Assim como a respiração humana tem um ritmo basal, o corpo humano em

10 termo fonológico glide se refere ao uso do fonema tanto como vogal quanto como consoante.

TradTerm, São Paulo, v. 33, junho/2019, p. 141-159 
movimento tende ao equilíbrio geométrico, pois é guiado pela proporção áurea $^{2}$ que rege as suas partes, portanto, deduzi que o movimento da fala também tenderia a compensar o tempo de duração das sílabas por inércia. Esta noção advém do critério árabe, pelo qual o sintagma prosódico se divide em unidades sonoras de movimento (sabab, "corda"), suspensão do movimento com ênfase (watid, "estaca") e inércia (não grafado, "i"), unidades que formam os pés rítmicos que, em seu movimento "encampam a tenda (bayt) da unidade de versificação" (SÁNCHEZ-SANCHA 1984-85: 57). Neste caso, teríamos:

Senh/ or/ /quea/ ro/ maé/esse? Vemd a/ca/te /quese/ ou /doa /lém?

Não pensei nisso ao elaborar o verso, porém, é possível verificar que cada hemistíquio tem aproximadamente sete sílabas sonoras, incluindo como "sílaba" a pausa da inércia no terceiro som, 3 (i). A inércia existe não somente no silêncio, mas também na continuação do movimento prosódico, como no caso do som 11(W)(i), /quese/, porque se lê "quézi" e o "e" é apenas continuidade do som. A diferença entre 11 "quese" (w) e 7 "esse" (S), é que no primeiro caso a consoante "q" é antecedida de uma quebra fonológica: cate/quese. Por isso é uma "estaca" (watid) que cria ênfase, enquanto no segundo caso há apenas continuidade e modulação prosódica: "aromaéesse". A inércia é o elemento neutro que abre espaço para o movimento prosódico acontecer de forma fluida; não tem medida fixa e é ajustável, por isso utilizo os espaçamentos para reforçar e reconstituir em português esse modus operandi do verso persa na sua dinâmica recitativa.

Se eu tivesse me limitado ao ritmo teria desistido de traduzir, mas prossegui, pois sabia também que para os místicos o estágio sensorial é apenas funcional. Não importa o signo em sua estrutura pura e sim o que se constrói com ele ou como ele conduz ao que está por detrás de si. Apesar de a polissemia do verso persa ser funcional na oralidade, o sentido "literal" não é tão difícil de se determinar, exceto no caso de empacarmos em expressões ou termos de época muito nebulosos. Rumi escreveu no mesmo persa moderno que é utilizado hoje em dia como idioma oficial do Irã e do Tadjiquistão e como dialeto no Norte do Afeganistão, só que no registro da Anatólia dos anos 1300. Muitos empréstimos turcos e árabes já caíram em desuso na atualidade. Portanto, nesse estágio, foi de grande valia ter à mão, na biblioteca da USP e online, um bom dicionário do persa

2 "Proporção áurea" é um dos termos utilizado para definir a constante real algrica irracional, também conhecida como $\mathrm{PI}$, arredondando, 1,618, a proporção entre parte maior e intermediária e intermediária e menor. 
histórico e literário (STEIGASS 1984). A versão literal a que cheguei, dividindo os hemistíquios em coplas para facilitar a sua disposição na página, é a seguinte:

Senhor esse perfume delicioso vem pelo prado da alma/ homilia de alguém? Ou será que vem de fora, do além-mundo?

Ó Senhor, essa água da vida vem brotando de qual terra natal?

ó Senhor, essa luz dos atributos vem vindo de que lugar?

Incrivel esse clamor da trupe de anjos que se eleva! Incriveis essas gargalhadas das huris do paraíso se ouvem!

Que audição é essa que faz a alma dançar girando? Que refúgio é esse, em que o coração bate as asas?

Quem casa? Qual o dote? 0 que o céu descortina? A lua aparece dourada feito uma insígnia.

Que caçada é essa em que se atira o destino? Se não é assim, por que ouço alto/ o tanger do arco?

Novas! Novas! Todos os amantes batendo palmas. Que vieram de mãos dadas e agora aplaudem.

No compasso celestial, o chamado da paz se eleva.

De novo, do mar, feito ondas, a fantasia vem chegando. 
Os olhos da fortuna estão embriagados pela fortuna dos vossos

a exemplo do que avistam, entram em contemplação.

Mova-te/sai deste mundo de fome, pois dentro dele

por causa de dois ou três pães estão esfaqueando.

Quem é mais feliz do que a alma? A vida gela de medo do corte.

A partida desola. Mas por que seria pior o que advém?

Cada qual no seu assombro e o meu assombro é o seguinte:

Quem nada guarda em seu âmago como ao âmago chega?

Já faço o bastante, pois não vou explicar o sopro de zéfiro.

De que servem os esclarecimentos? A alma manifesta-se por si só chegando.

Acontece que o acesso ao sentido "literal" já nasceu cotejado com o de outras traduções. Eu tinha em mãos a seguinte tradução, de 1968, de Arthur John Arbery (RUMI 2009: 123-124), para o inglês:

Lord, is this sweet scent coming from the meadow of the soul, or is it a breeze wafting from beyond the world?

Lord, from what homeland does this water of life bubble up? Lord from what place comes this light of the attributes?

Amazing! Does this clamour arises from the troop of the angels? Amazing! Does this laughter come from the houris of paradise?

What concert is it, that soul spins round dancing? What whistle is it, that the heart is coming flapping winds?

What a marriage feast is it! What a wedding! Heaven is like a curtain; the moon with this plate of gold for a sign is coming.

What a hunt! For the arrow of fate is flying; if it is no so, why comes the song of the bow?

Good news, good news, lovers all! Clap your hands, for he who once escaped from your hands is coming clapping. 
From the fortress of the skies the cry of "safe quarter" is arising, and from the sea such a wave of fear is coming.

The eye of prosperity is intoxicated with your approaching; this is proof that is obvious to the eye.

Escape from this world of death, where lances strike for the sake of two or three loaves.

What is fairier than life? Yet it should go, have no fear; why do you grieve about its departing, seeing that better than is coming?

Every man is amazed at something; my amazement is, how it is when He enters the midst, $\mathrm{He}$ is not contained in the midst.

Let me have done. Though it is a cipher, I Will not explain it; what are you trying to explain? The soul of explanation is coming.

E de Eva de Vitray-Meyerovitch, em parceria com Mohamad Mokri (Ruml 1973: 308-309), tinha a seguinte tradução para o francês:

O mon Dieu, ce perfum suave vient-il du jardin de l'âme?

Ou bien est-ce une brise arrivant de l'au-delà du monde ?

O mon Dieu, de quelle patrie jaillit cette source de vie ?

O mon Dieu, cette lumière de Tes attributs, de quel lieu provient-elle?

Oh ! Merveille! Ce tumulte s'élève-t-il des cohortes angéliques?

Ces éclats de rire cont-ils ceux des Houris du Paradis ?

Quel est ce samâ' qui fait danses les âmes?

Quel est ce sifflet qui fait venir se poser le coeur à tire d'aile?

Qui est la jeune mariée, quelle est la dot, que le firmament ressamble à un dais nuptial ?

La lune vient apportant un plat rempli de pièces d'or.

Quelle est la proie que perce a flèche du destin ?

S'il n'est pas ainsi, d'ou vient la plainte de l'arc?

Heureuse nouvelle, ô amoureux ! Battez des mains !

Celui qui s'était échappé de nos mains revient en applaudissant.

Du haut des hamparts du ciel s'élève le cri : « faites-nous merci »!

Du côte de l'océan arrive la houle des pensées.

Les yeux de la Fortune sont éblouiss par votre bonheur ;

Cela prouve qui'il se manifeste à tous les yeux.

TradTerm, São Paulo, v. 33, junho/2019, p. 141-159 
Vous avez échappé à ce monde de famine.

Où quelques morceux de pain se conquièrent de haute lutte.

Quoi de meilleur que l'âme ? Pourtant, quand elle s'en va, n'aie point de souci.

Porquoi t'affliger de son départ, puisque vient le remplacer quelque chose qui vaut mien encore?

Chacun s'étonne, et moi aussi je m'emerveille, de ceci :

Celui que nul ne peut contenir, comment est-il contenu dans le coeur?

Je me tais ; c'est un mystère : je ne l'explique pas.

Que ferais-tu de l'explication, quand vient l'âme de l'explication ?

Ter como referência tais traduções me dividia internamente, na medida em que eu não podia fiar tanto de sua literalidade, logo não me oferecia segurança com relação ao "segundo estágio", além de que me impeliam a pensar sobre os seus modos de construir a "casa" poética do símbolo. A tradução francesa, por exemplo, não agrupava os versos vertidos dos hemistíquios em coplas, como a inglesa. Por outro lado, eu estava sujeita a lidar com o que elas suscitavam em mim em relação ao registro de linguagem e escolhas semânticas, atirando para estados que correspondiam aos estágios quarto e quinto da audição, respectivamente a variabilidade de sentidos e a dualidade interna, antes do terceiro, em que a identificação projetiva e o estado afetivo devem preponderar. A tradução inglesa soa mais explicativa, enquanto a francesa mantém o estrangeirismo samâ' para o que Arberry chama de concert, em referência ao ritual da audição mística sufi. Diferentemente da autora francesa, o pesquisador britânico não é um iniciado sufi e, informado pela definição histórica do termo, verte o seu significado pelo sentido musical numa postura, digamos, mais científica com a qual eu me identificava e, ao mesmo tempo, cujo alcance eu questionava. Por outro lado, embora meu conhecimento nesses idiomas não seja suficiente para uma apreciação técnica, sentia o verso de Meyerovitch mais musical e, não obstante, isso não parece advir de uma escolha deliberada em marcar a identidade musical ou oral do verso de Rumi, mas de uma tendência francófona de evidenciar as qualidades intrínsecas da cantilena da língua francesa. Também me pareceu que a francesa cotejou seu texto com o inglês antes de finalizá-lo e nenhum dos dois ousou a recriação, embora em ambos possamos notar o movimento subjetivo por detrás das escolhas semânticas.

Como se vê, é impossível olhar o aspecto semântico sem ir além da exploração apenas bilateral entre a língua de partida e a de chegada. 0 direcionamento dado por leituras em outros idiomas me impelia internamente a um posicionamento cultural e histórico que supostamente 
só deveria vir nos estágios posteriores da audição, especialmente o quinto, em que se inicia o distanciamento subjetivo e o ato de observar a si mesmo e aos demais tradutores como sujeitos históricos em suas diferentes dinâmicas de reconstituição do sentido discursivo do poema.

Em realidade, foi por ater-me à dimensão retórico-formal num sentido mais profundo que pude explorar uma chave de compreensão sobre as escolhas semânticas e discursivas e perceber seu efeito na estrutura do poema. No gazal persa, o verso de abertura costuma conter uma síntese do poema e por isso ali o estabelecimento do sentido é crucial. Uma vez que o poema é extático e a própria inspiração faz parte de sua temática, a dimensão conceitual das escolhas relativas à homilia, alma e além-mundo, afetaria sensivelmente o sentido do poema como um todo. Contudo, neste caso em particular o segundo verso também é fundamental, pois o autor se refere à nascente dos atributos divinos e da água da vida como uma expansão do tema. Enquanto Arberry fala de water of life, Meyerovitch se exprime em termos de source de vie e mais: os atributos se tornam em sua fala Tes attributs, o que confere ao poema um tom mais religioso.

Neste aspecto, considero minha tradução profundamente subjetiva. Invertendo a função da linguagem, ative-me ao sentido metafórico do termo "terra natal" (watan) como sendo literal e tomei o de prado e/ou homilia como metafórico, traduzindo-o por sinonímia como "catequese". Fiz tal inversão movida pela combinação das imagens que me remetia ao nosso sincretismo e histórico de conversão indígena que os mapuches da fronteira Sul entre Chile e Argentina definiram num ditado: "cuándo vinieron, ellos tenían la Bíblia y nosotros teníamos la Tierra. $Y$ nos dijeron, cierren los ojos y recen. Cuando abrimos los ojos, nosotros teníamos la Biblia y ellos tenían la Tierra". A escolha foi muito pessoal porque a Terra do Fogo é minha própria terra natal e foi graças ao leite de uma mapuche que pude sobreviver quando pequena. Essa interpretação do verso de Rumi a respeito da "origem" não é anti-espiritual, mas existencial e busca ressituar historicamente o seu discurso na perspectiva imanente dos povos originários, para os quais não faz sentido abstrair o espírito da natureza. 0 poema como um todo é microcosmo simbólico do mundo onde a vida emerge como um fenômeno assombroso, portanto creio ser cabível realizar tal transgressão sob a justificativa da "sobreposição" arquetípica de traço existencial do tradutor sobre $o$ autor.

Também seria pertinente manter na minha tradução a bipartição do verso e sinalizar com clareza as funções de entrada, transição central e saída, que são fundamentais para localizar os constructos simbólicos na distribuição espacial do poema. Acontece que a minha identificação projetiva me levou a reorganizar as imagens poéticas numa forma arquetípica adaptada ao meu modo de significar. A opção não foi tão 
absurda, considerando que a visualidade é igualmente relevante na cultura persa, mas para o gazal, que é por definição uma forma de canto, dei uma solução visual:

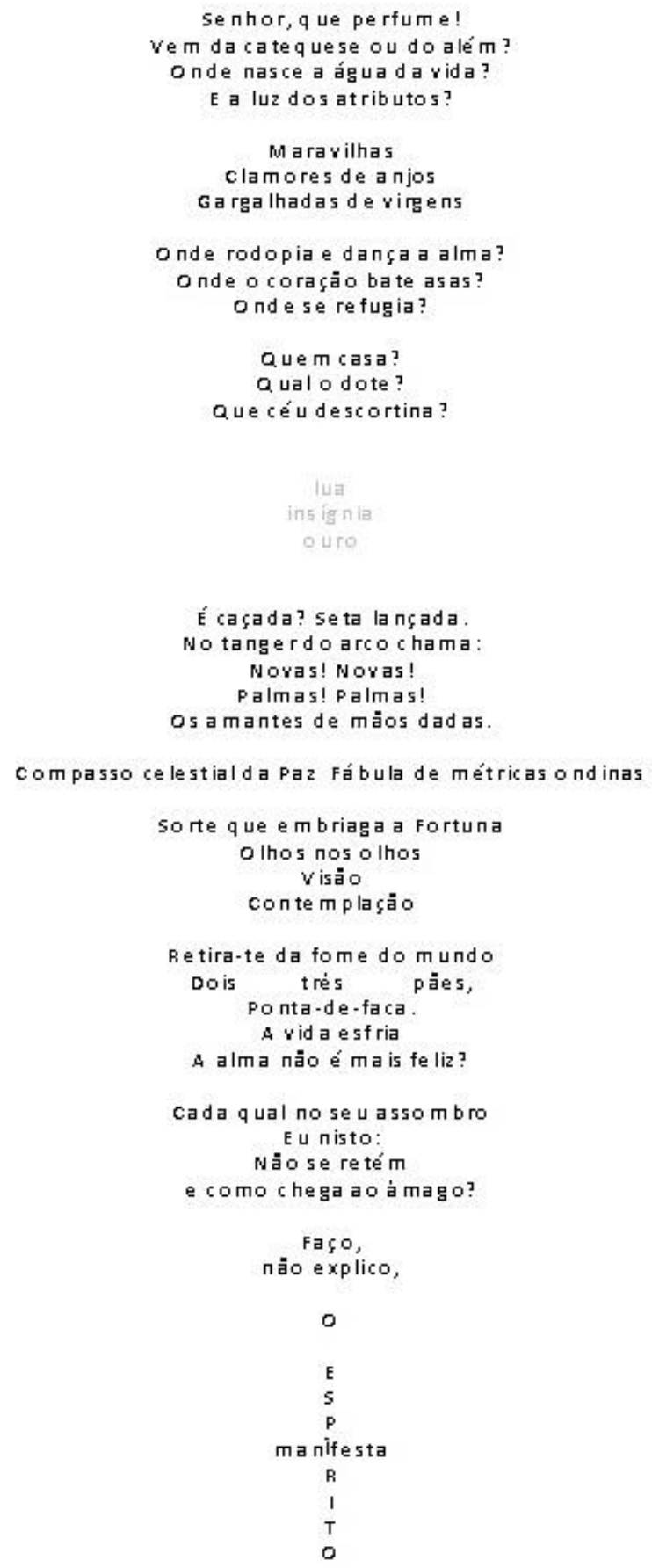

Escolhi a disposição centralizada e verticalizada para representar a água da vida em sua fluidez, originada no plano divino ou celestial, penetrando e fertilizando o mundo fenomênico abaixo, cujas formas emergem em sua passagem. 0 centro espacial do poema se torna ponto de convergência das imagens em paralelismo, especialmente o tesouro, o 
núcleo e a lua, esta última redonda e dourada feito esfera perolada, que é uma das imagens simbólicas centrais da alma na mística sufi.

Minha relação aqui com o poema original é interativa. Eu "ouço" o que o poeta diz como uma sugestão ou dica para a recriação dos seus próprios versos na minha língua. Assim, ao ler o verso $9^{\circ}$, que se refere à visão embriagadora que contempla sendo contemplada, assumi o propósito de "fazer ver" a ideia poética da manifestação do espírito na matéria pela imagem da cruz, pontuando a referência cristã do tesouro celestial no coração do homem. 0 simbolismo se inicia pelo artigo "O", que seria signo do círculo e símbolo do "Uno", de onde o 'espírito' desce cruzando a palavra 'man-i-festa', na horizontal por 'man-' ('homem' em inglês, 'eu' em persa) e 'festa' com um alef (I) ao centro, signo sufi da retidão espiritual. Neste sentido, o "verso" final do poema simboliza a unidade atingida pela retidão interior em meio à multiplicidade.

0 verso de transição, oitavo, divide o poema num sentido cosmológico. Justamente nesse ponto o poeta se refere à métrica e à versificação, espelhando na sintaxe bipartida dos hemistíquios os elementos antitéticos compasso/ondinas, celestial/métrica, paz/fábula. Tal disposição sugere que o ritmo da vida segue a 'régua' do céu:

Compasso celestial da Paz Fábula de métricas ondinas

Com isso, evidencia-se o contraste e a oposição entre o compasso do tempo cósmico acima que ordena e estabiliza, e o ritmo das ondas aquáticas e de tudo que habita o plano terreno ou sublunar abaixo. Da ótica mística, a poesia é manifestação mundana do domínio da fábula e se caracteriza por mutação, instabilidade e impermanência. É dessa emanação rítmica que a Fortuna se embriaga ao contemplar no humano o assombro daquilo que 'não se entesoura' (neganjad). 0 verso alude ao hádice qudsi: "Eu era um tesouro oculto, quis ser conhecido e criei o mundo", argumento islâmico da Criação divina que remete também ao sermão da montanha:

Não ajunteis tesouros na terra, onde a traça e a ferrugem tudo consomem, e onde os ladrões minam e roubam; mas ajuntai tesouros no céu, onde nem a traça nem a ferrugem consomem, e onde os ladrões não minam nem roubam. Porque onde estiver o vosso tesouro, estará também o vosso coração. (Mateus 6:19-21)

Também o reino dos céus é semelhante a um tesouro escondido num campo, que um homem achou e escondeu; e, pelo gozo dele, vai, vende tudo quanto tem, e compra aquele campo. (Mateus 13:44)

TradTerm, São Paulo, v. 33, junho/2019, p. 141-159 
Ao traduzir o $12^{\circ}$ Verso, em que se aborda o "entesourar-se", Arberry sugere a contemplação do Ser supremo através de si mesmo da seguinte forma: He enters the midst, He is not contained in the midst. Deus penetra a criação através do atributo da Beleza, mas não pode ser abarcado por ela e nem explicado didaticamente por meio de homilias. Meyerovitch insere um coeur para definir esse centro receptor, mas isso é uma metáfora explicativa, enquanto o propósito do poeta parece ser desativar o anseio explicativo para dar lugar a uma "ação", conforme se deduz deste diálogo:

O emir disse: "a raiz da questão é a ação".

Rumi disse: Onde está o povo da ação, para que eu possa ensiná-lo a agir? Veja como você esquenta as orelhas com palavras no lugar de ações. Se eu tivesse parado de falar agora, você ficaria transtornado. Torne-se um buscador da ação, então posso lhe mostrar a ação!

Estou buscando pelo mundo todo discípulos para ensiná-los a ação, mas não encontro quem a conheça. Todos se ocupam somente de palavras, então me ocupo de palavras. O que você sabe da ação? A ação só se conhece através da ação. Não há viajante nesta via - está vazia - então como alguém irá saber o verdadeiro modo de agir?

E depois, oração e jejum não são ações, são formas de ação. A ação é uma realidade interna (RUMI 1961: 133-134).

Arberry traduziu este diálogo (de quem retraduzo), por isso compreendo a sua opção por não metaforizar o "núcleo". Para o poeta, somente o verbo divino pelo qual Deus criou o mundo é ação, daí que o seu poema é uma forma muito peculiar de homilia, cuja resposta labiríntica e paradoxal nada explica senão apenas sinaliza que o espírito manifesta-se por si mesmo. $\mathrm{O}$ ato verbal criador, que eu compreendo como algo relacionado ao silêncio, é a árvore de onde nascem os frutos da linguagem e suas sementes, as palavras. A palavra pode ser inócua ou estimular o ato interior e, neste sentido, a noção de Rumi ecoa algo da parábola do semeador:

E o que foi semeado entre espinhos é o que ouve a palavra, mas os cuidados deste mundo e a sedução das riquezas sufocam a palavra, e fica infrutífera. Mas o que foi semeado em boa terra é o que ouve e compreende a palavra; e dá fruto, e um produz cem, outro sessenta, e outro trinta. (Mateus 13:22-23)

Para Rumi, somente a palavra humana nascida da experiência tem essa característica. E de que forma ela em si mesma se torna ato fecundo? 
Se você só reconhece os atributos gerais, não observando a beleza particular, não é apropriado argumentar-lhe, pois nossas palavras vão misturadas com a beleza e é errado revelar a beleza para aqueles que não a apreciam. Esta é a ciência do potencial e não a ciência da argumentação. (RUMI 1961: 276)

Ou seja, para o mestre dançarino o belo veicula o verdadeiro. Neste sentido, a palavra poética é ação, porque move a audiência a experimentar, por meio da imaginação, aquela dimensão interna explorada na ascese mística. Eis a dança de seus versos. Este é o motivo pelo qual não podemos abandonar o cuidado com aspectos formais na tradução dos seus poemas. Ao mesmo tempo, como dar conta de sinalizar a natureza da ação estética naquela acepção mística? Na minha tradução final (revisada aqui) que respeita mais a forma arquetípica do original, verto o "centro" de onde a ação nasce, como o "âmago" do "Mistério Tremendo", termo que adiciono para dar conta do assombroso e do enigmático na criação divina:

\section{Senhor que aroma é esse?}

Qual a terra natal da água da vida?
Vem da catequese ou do além?

Qual a estação da luz dos atributos?

Incríveis clamores de anjos! Incríveis gargalhadas de virgens!

Em que samá dança a alma? Em que refúgio bate asas?

Quem casa? Qual dote? Qual sorte? No céu a lua doura à insígnia

Quem acerta no destino? Não soa alto o tanger do arco?

Novas! Novas! Palmas! Palmas! Todos os amantes de mãos dadas

Do passo celestial vem a Paz Do mar as fábulas ondinas

A Fortuna se embriaga da visão Olhos nos olhos contemplação

Retira-te da fome do mundo Dois três pães ponta-de-faca!

Quem é mais feliz que o espírito? A vida esvai teme-se a partida

A todos fascina Mistério Tremendo chega ao âmago nada o retém

Basta de insinuar É claro em si o espírito manifesto

Observando o processo dessa tradução, por meio dos exemplos pontuais que destaquei de um caminho mais complexo (e também confuso), concluo que não segui as etapas místicas sistematicamente. 0 meu primeiro contato com o poema traduzido sequer foi sensorial, pois na realidade eu já tinha 
conhecido o poema em traduções para outras línguas e, além disso, estava munida de diretrizes compositivas e teóricas, bem como de referências históricas e documentais da época. À primeira vista, eu estava poluída por diversos elementos exteriores que tornavam impura e invertida a minha audição, no sentido de que eu não segui a ascese direta de uma tradutora puramente intuitiva, como almejaria talvez um sufi. Para dizer a verdade, eu já comecei de algum ponto entre o terceiro e o quinto estágios preconizados por Alghazali e as intuições surgiam aleatoriamente ou atreladas à operação conjunta de aspectos técnicos e conceituais, sem que a minha prática pudesse exemplificar um método, digamos, tipicamente sufi para a tradução.

Note que o cotejamento com as demais traduções e as reflexões semânticas se deram de forma desordenada ou impregnadas por outros elementos, e as soluções formais e discursivas também, ora ao modo do quinto estágio, da desidentificação subjetiva, ora ao modo do sexto estágio, da autoconsciência que ocorre como historicidade e alteridade. Não obstante, a abordagem do texto não se restringiu nunca a um perscrutar histórico-linguístico nem a consciência do histórico se limitou à investigação bibliográfica e documental na medida em que se concebeu a própria marca da transgressão como registro da ressignificação histórica. Ademais, sinto que as transgressões é que, paradoxalmente, refletiriam algo mais próximo do que seria o sétimo estágio, isto é, do estado unitivo, pois consistem em escolhas movidas por um desejo de profunda integração do outro no eu, do autor no tradutor; nesse sentido extáticas e como tais transbordamentos tradutórios que expressam a fusão entre o sentido original e o sentido atualizado do texto em fluxo na recriação poética. Contudo, todas se deram de forma pontual numa oscilação de estados descontínuos; em todo caso, me pergunto, afinal: qual apreensão poética pode ser realmente sistemática? Com efeito, a ambição de pureza, nesse sentido, é antimística porque instaura um estado de não-comunhão com tudo que já é e estabelece níveis para a apreensão que, em realidade, não se dá em níveis. Estados e estágios são apenas parâmetros de processos intuitivos que não têm trajetória definida, mas que podem igualmente estar em foco no ato tradutório.

0 ápice da minha atividade imaginativa e intuitiva me levou à recriação absoluta da forma do poema e, depois, o propósito da oralidade me levou de volta ao formato mais próximo do original. Contudo, importa se a leitura visual muda a recitação? Para testar isso eu teria de ter produzidos textos idênticos e não o fiz, mas o que importa para mim é qual deles seria mais eficaz em qual ocasião. Penso que a ação da pureza é a honestidade e que as melhores intuições surgem de interações diretas e livres com o poema, o que nos leva a seguir os desígnios do poeta de um jeito criativo, vertendo a 
sua mensagem espiritual na nossa própria linguagem poética em função de um diálogo tácito, da conversa sem palavras que se dá como num jogo.

\section{Referências bibliográficas}

Adonis. Sufismo y surrealismo. Tradução de José Miguel Puerta Vílchez. Madrid: Ediciones del Oriente y del Mediterrâneo, 2008. Tradução de José Miguel Puerta Vílchez.

ALGHAZALI. "Emotional religion in Islam as affected by music and singing" In: Journal of the Royal Asiatic Society of Great Britain and Ireland, v. 33. Tradução de Duncan Black McDonald. Hartford: Hartford Seminary Foundation, 1938.

DeO, A.; KIPARSKY, P. "Poetries in Contact: Arabic, Persian, and Urdu." Palo Alto: Stanford University Press, s/d. Disponível em: <http://www.stanford.edu/ kiparsky/Papers/tartu.pdf>. Acesso em: 06 dez. 2018.

DiltheY, W. El mundo histórico. México: Fóndo de Cultura Económica,

IBN ARABI. The bezels of wisdom. Tradução de Ralph Austin e prefácio de Titus Burckhardt. New Jersey: Paulist Press, 1980. Tradução de Ralph Austin e prefácio de Titus Burckhardt.

Kahnemuyipour, A. Persian Ezafe Construction: Case, Agreement or something else. Syracuse: Syracuse University, 2006. Disponível em: <http://www.iranianlinguistics.org/papers/IranConference_2006.pdf> . Acesso em: 06 dez. 2018.

Meschonnic, H. Critique Du rythme. Anthropologie historique du langage. Lagrasse : Verdier, 1982.

Ruml. Discourses of Rumi. Tradução Arthur John Arberry. Ames, lowa: Omphalokepsis, 1961.

- [Jalal al-Din Rumi, Maulana. Divan-I Shams-I Tabrizi. English. Selections.] Mystical poems of Rumi. Tradução Arthur John Arberry; anotações Hasan Javadi; correções Franklin Lewis; edição geral Ehsan Yarshater. NY: University of Chicago Press/Unesco, 2009.

- [Mawlânâ Djalâl Od-dîn Rûmî. Dîvân-E Shams-E Tabrîzî]. Odes Mystiques. Tradução e notas Eva de Vitray-Meyerovitch e Mohammad Mokri. Paris : Éditions du Seuil/Unesco, 1973.

. Kulliāt-I Shams yā Dīwān-I Kabīr. Edição persa de Badî‘ AlZamân

Furûzanfar. Teheran: Amir Kabîr, 1957.

TradTerm, São Paulo, v. 33, junho/2019, p. 141-159 
SÁNCHEZ SANCHA, A.. Introducción exegética a la métrica tradicional árabe. In: Awraq yadida, n. 7-8, Madrid: Instituto Hispano-Arabe de Cultura, pp. 48-173. 1984-1985.

STEIGASS, F. J. Comprehensive Persian-English Dictionary, including the Arabic words and phrases in Persian Literature, being Johnson and Richardson's Persian, Arabic and English Dictionary (Oxford, 1777-80) revised, enlarged and entirely reconstructed. London/Boston/Melbourne/Henley: Iran University Press/ Routledge \& Kegan Paul, 1984.

YUNIS, L. E. Samatradução: a dança num exercício de tradução do gazal de Jalal Uddin Rumi. Tese (Doutorado em Letras) - Faculdade de Filosofia, Letras e Ciências Humanas, Universidade de São Paulo, São Paulo, 2017.

Recebido em: 10/12/2018

Aceito em: 14/05/2019

Publicado em junho de 2019 